
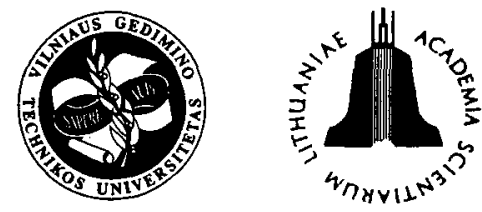

ISSN 1392-3730

JOURNAL OF CIVIL ENGINEERING AND MANAGEMENT

http:/www.vtu.lt/english/editions

2003, Vol IX, No I, 59-67

\title{
CONSTRUCTION PROJECTS MANAGEMENT EFFECTIVENESS MODELLING WITH NEURAL NETWORKS
}

\author{
Rasa Apanavičiené $\dot{1}^{1}$ Arvydas Juodis ${ }^{2}$ \\ Dept of Civil Engineering Technologies, Kaunas University of Technology, \\ Studentu g. 48, LT-3031 Kaunas \\ 1 E-mail: ras_apanaviciene@hotmail.com; 2 E-mail:a.juodis@takas.lt \\ Received 14 Oct 2002; accepted 05 Febr 2003
}

\begin{abstract}
The paper deals with important aspects of construction management key factors identification and their relative significance for the construction projects management effectiveness. The approach of artificial neural network allows the construction projects management effectiveness model to be built and to determine the key determinants from a host of possible management factors that influence the project effectiveness in terms of budget performance.

A list of construction management factors was collected according to the results of past research and opinion of experienced construction management practitioners. A survey questionnaire was compiled and distributed to construction management companies in Lithuania and the USA. The historical data of construction projects performance have been used to build the neural network model. Altogether twelve key construction management factors were identified covering areas related to the project manager, project team, project planning, organization and control. Based on these factors, the construction projects management effectiveness model was established. The application algorithm of that model is presented.

The established neural network model can be used during competitive bidding process to evaluate management risk of construction project and predict construction cost variation. The model allows the construction projects managers to focus on the key success factors and reduce the level of construction risk. The model can serve as the framework for further development of the construction management decision support system.
\end{abstract}

Keywords: construction projects management, artificial neural networks.

\section{Introduction}

The construction projects are delivered under conditions of uncertainty and risk in the competitive market environment. The external and internal risks are addressed to the construction projects. The external risk consists of economic risk, political risk, financial risk and environmental risk. The internal risk consists of project technical-technological risk, legal risk and management risk. The paper analyses internal management risk of the construction projects.

Project management risk is related to the institution of the project management: its competency, experience, strategic and tactic decisions made during the construction project delivery. Managing a collection of projects at the portfolio level the executive managers of construction management company try to evaluate management risk and predict the effectiveness of potential projects outcomes.

Project management risk and effectiveness depend on the certain factors of the project management system. Construction projects management effectiveness factors are analysed by different authors and from different perspectives. There are three main trends in determining construction management key factors research:

1. determining key factors identification for construction projects success [1-5];

2. determining key factors identification for a particular group of construction projects success, eg, BOT, design-build [6-9];

3. particular factors impact on construction projects success $[10-17]$.

Predictive models developed to identify the key factors and to measure their impact on overal projects success were using regression and correlation techniques, factor analysis, Monte-Carlo simulation, experts and multiply criteria evaluation systems $[18,19]$. Essentially, in these approaches the functional relationships between the input factors and project outcome is assumed and tested against the data. The relationships are modified and retested until the models that best fit the data are found.

The neural network approach does not require an a priori assumption of the functional relationship. Artifi- 
cial neural networks are very useful because of their functional mapping properties and the ability to learn from examples. Multilayer neural networks have been shown to have a certain "universal" approximation property. Networks have been compared with many other functional approximation systems and found competitive in terms of accuracy [20]. This and the ability to learn from examples allow modelling the complex construction projects management system where behavioural rules are not known in detail and are difficult to analyse correctly.

The construction projects management effectiveness neural network model established by the authors of the paper can be used during competitive bidding process to evaluate management risk of construction project and predict construction cost variation. The model allows the construction projects managers to focus on the key success factors and reduce the level of construction risk. The model can serve as the framework for further development of the construction management decision support system.

\section{Methodology of artificial neural networks (ANNs)}

The foundation of artificial neural networks (ANN) paradigm was laid in the 1950 s, and ANN have gained significant attention in the past decade because of the development of more powerful hardware and neural algorithms [21]. Artificial neural networks have been studied and explored by many researchers where they have been used, applied, and manipulated in almost every field. For example, they have been used in system modelling and identification, control, pattern recognition, speech pronounciation, system classifications, medical diagnosis as well as in prediction, computer vision, and hardware implementations. As in civil engineering and management applications, neural networks have been employed in different studies. Some of these studies cover the mathematical modelling of non-linear structural materials, damage detection, non-destructive analysis, earthquake classification, dynamical system modelling, system identifications, and structural control of linear and non-linear systems, construction productivity modelling, construction technology evaluation, cost estimation, organisational effectiveness modelling and others [22, 23].

A neural network can be defined as a model of reasoning based on human brain [24]. Table 1 shows the analogy between biological and artificial neural networks.

Table 1. Analogy between biological and artificial neural networks

\begin{tabular}{|c|c|}
\hline $\begin{array}{c}\text { Biological neural } \\
\text { network }\end{array}$ & $\begin{array}{c}\text { Artificial neural } \\
\text { network }\end{array}$ \\
\hline Soma & Neuron \\
Dendrite & Input \\
Axon & Output \\
Synapse & Weight \\
\hline
\end{tabular}

Learning is fundamental and essential characteristic of biological neural networks. The ease with which they can learn led to attempts to emulate a biological network in a computer.

Model of artificial neural network. An artificial neural network consists of a number of very simple and highly interconnected processors, also called neurons, which are analogous to the biological neurons in the brain. The neurons are connected by weighted links passing signals from one neuron to another. Each neuron receives a number of input signals through its connections; however, it never produces more than a single output signal. The output signal is transmitted through the neuron's outgoing connection (corresponding to the biological axon). The outgoing connection, in turn, splits into a number of branches that transmit the same signal (the signal is not divided among these branches in any way). The outgoing branches terminate at the incoming connections of other neurons in the network. Fig 1 represents connections of a typical ANN.

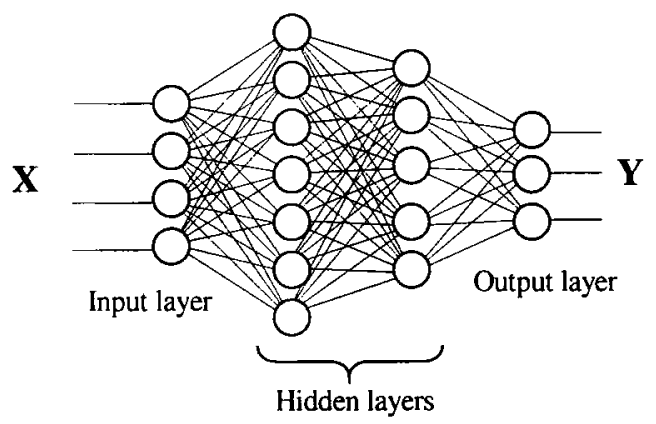

Fig 1. Architecture of a typical artificial neural network

As shown in Fig 1, a typical ANN is made up of a hierarchy of layers, and the neurons in the networks are arranged along these layers. Each layer in a multilayer neural network has its own specific function. The input layer accepts input signals from the outside world and distributes them to all neurons in the hidden layer. These neurons detect the features; the weights of the neurons represent the features hidden in the input patterns. These features are then used by the output layer for determining the output pattern. The output layer accepts output signals from the hidden layer and establishes the output pattern of the entire network.

The neurons are connected by links, and each link has a numerical weight associated with it. Weights are the basic means of long-term memory in ANNs. They express the strength, or, in the other words, importance of each neuron input. A neural network "learns" through repeated adjustment of these weights.

The network in Fig 1 is fully connected and has a feedforward structure, meaning there are no connection loops that would allow outputs to feedback to their inputs, although a recurrent neural network has feedback loops from its outputs to its inputs. 


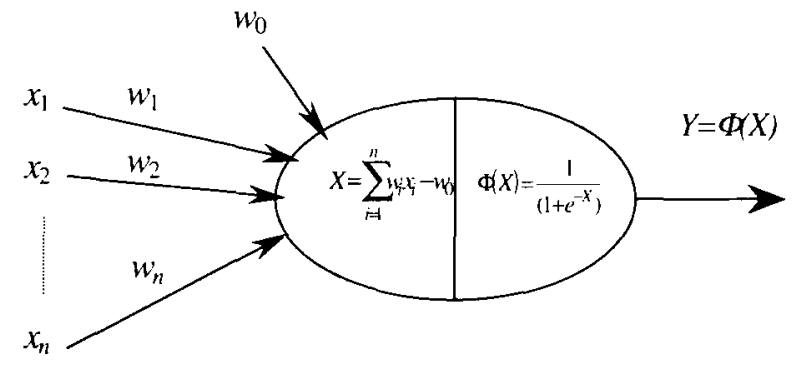

Fig 2. Diagram of an artificial neuron

Model of artificial neuron. The artificial neuron is the basic computing element of the ANN (Fig 2).

Fig 2 represents diagram of an artificial neuron, where $x_{1} \ldots x_{n}-$ input signals; $w_{1} \ldots w_{n}$; - weights; $w_{0}$ threshold value; $\Phi(X)$ - transfer (activation) function; $X$ weighted sum of the input signals; $y$ - output signal.

A neuron receives several signals from its input links, computes a new activation level and sends it as an output signal through the output links. The input signal can be a raw data or outputs of other neurons. The output signal can be either a final solution to the problem or an input to other neurons.

The neuron computes the weighted sum of the input signals and compares the result with a threshold value:

$$
X=x_{1} w_{1}+x_{2} w_{2}+\ldots+x_{n} w_{n}-w_{0}=\sum_{i=1}^{n} x_{i} w_{i}-w_{0}
$$

If the net input is less than the threshold, the neuron is not activated. But if the net input is greater than or equal to the threshold, the neuron becomes activated and sends the signal to other neurons. In other words, neuron uses the transfer or activation function. Many activation functions have been tested, but only a few have found practical applications - the step, sign, linear and sigmoid functions. Neurons with the sigmoid activation function are used in the back propagation networks. The sigmoid function transforms the input, which can have any value between plus and minus infinity, into a reasonable value in the range between 0 or -1 and 1 (Fig 3 ).

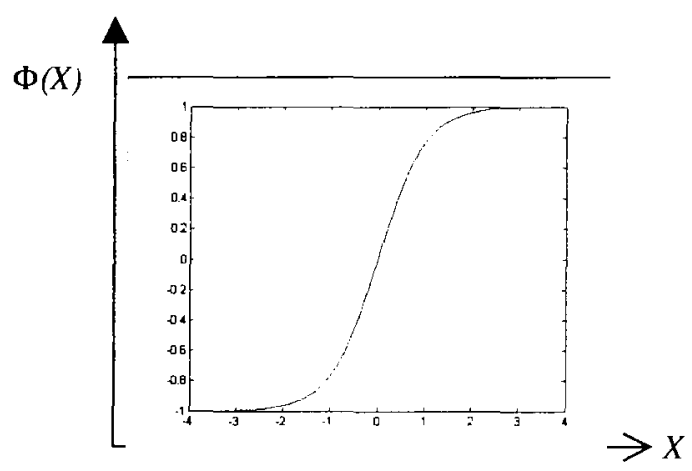

Fig 3. Sigmoid activation function
The actual output of the neuron with a sigmoid activation function can be represented as:

$$
\Phi(X)=\frac{1}{\left(1+e^{-X}\right)}=\left(1+e^{-X}\right)^{-1} .
$$

Modelling by applying $\boldsymbol{A N N}$. To build an artificial neural network, we must decide first how many neurons are to be used and how the neurons are to be connected to form a network. In other words, we must first choose the network architecture. Before training ANN, all the available data are randomly divided into a training set and a test set. Then we decide which learning algorithm to use. And finally we train the neural network, that is, we initialise the weight of the network and update the weights from a set of training examples. The error function is a useful indicator of the network's performance. The training algorithm attempts to minimise this criterion. When the value of the error function in a entire pass through all training sets, or epoch, is sufficiently small, a network is considered to have converged. Once the training phase is complete, the networks ability to generalise is tested against examples of the test set.

The architecture and size of a neural network depend on the problem complexity. The number of neurons in the input and output layers is decided by the selected inputoutput variables of the analysed system. The simulation experiments of neural network training and testing indicate the optimal number of hidden layers as well as the number of neurons in these layers.

The goal of neural network training is to find the functional relationship between the input patterns and target outputs. A training set of the input patterns and corresponding desired outputs or targets is presented to the network. The network computes its output pattern, and if there is an error - or, in other words, a difference between actual and desired output patterns - the weights are adjusted to reduce this error according to the learning law (algorithm).

More than a hundred different learning algorithms are available, but the most popular method is backpropagation. The backpropagation learning algorithm has two phases. First, a training input pattern is presented to the network input layer. The network then propagates the input pattern from layer to layer until the output pattern is generated by the output layer. If this pattern is different from the desired output, an error is calculated and then propagated backwards through the network from the output layer to the input layer. The weights are modified as the error is propagated. To derive the backpropagation learning law, let us consider the three-layer network, shown in Fig 4.

The indices $i, j$ and $k$ here refer to neurons in input, hidden and output layers, respectively. Input signals, $x_{1}$, $x_{2}, \ldots x_{n}$, are propagated from left to right, and error signals, $\mathrm{e}_{1}, \mathrm{e}_{2}, \ldots, \mathrm{e}_{l}$, from right to left. The symbol $w_{i j}$ denotes the weight for the connection between neuron $i$ in the input layer and neuron $j$ in the hidden layer, and 


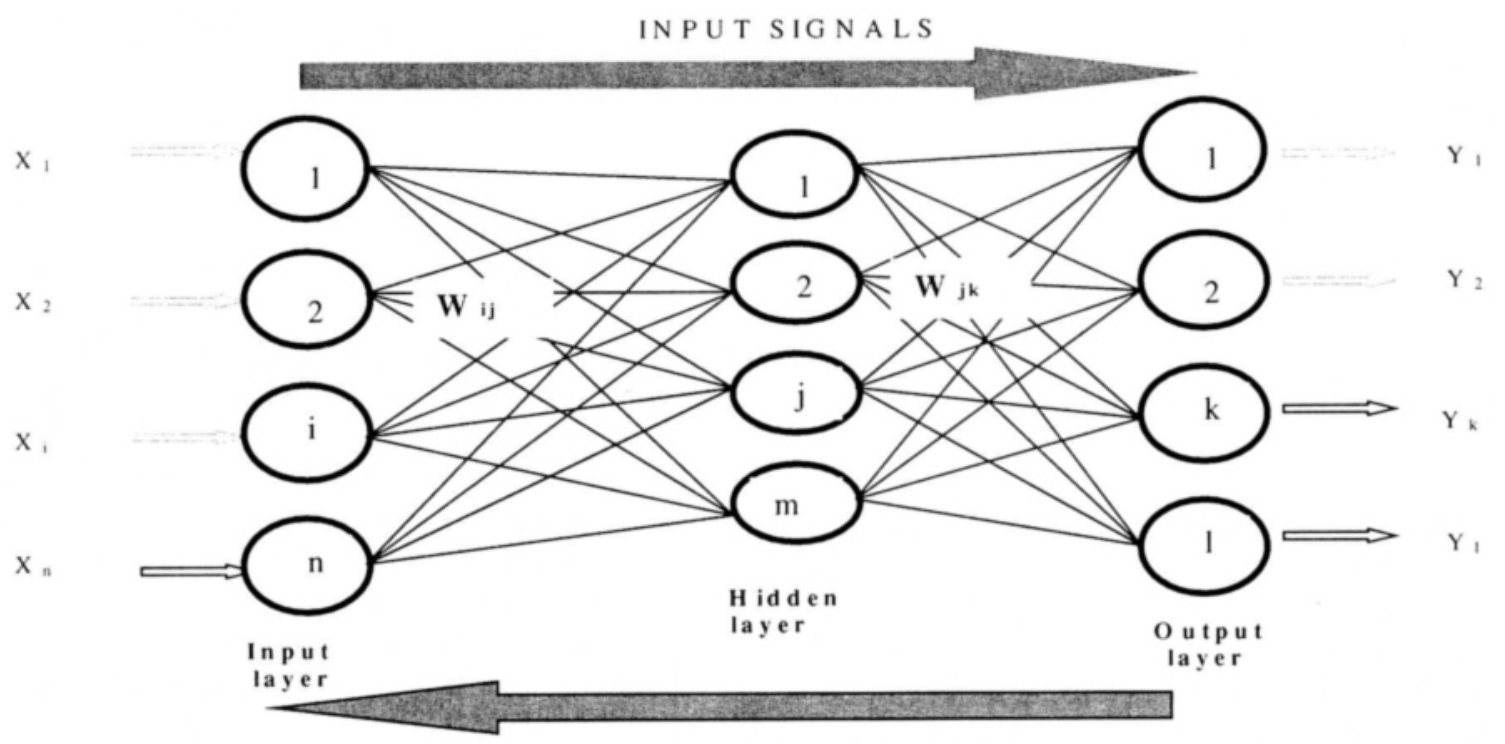

ERROR SIG NALS

Fig 4. The backpropagation learning law in the three-layer neural network

the symbol $w_{j k}$ the weight between neuron $j$ in the hidden layer and neuron $k$ in the output layer. lowing:

The backpropagation training algorithm is the fol-

Step 1: Initialisation. Set all the weights and threshold levels of the network to random numbers uniformly distributed inside a small range $\left[-2.4 / N_{i} ;+2.4 / N_{i}\right][21]$, where $N_{i}$ is the total number of inputs of neuron $i$ in the network.

Step 2: Activation. Activate the backpropagation neural network by applying inputs $x_{1}(t), x_{2}(t), \ldots, x_{n}(t)$ and desired outputs $T_{1}(t), T_{2}(t), \ldots, T_{l}(t)$, where $t$ is number of iteration.

A. Calculate the actual outputs of the neurons in the hidden layer $Y_{j}(t)$ :

$$
Y_{j}(t)=\operatorname{sigmoid}\left[\sum_{i=1}^{n} x_{i}(t) \times w_{i j}(t)-w_{o j}\right]
$$

where $n$ is the number of inputs of neuron $j$ in the hidden layer and sigmoid is the sigmoid activation function.

B. Calculate the actual outputs of the neurons in the output layer $Y_{k}(t)$ :

$$
Y_{k}(t)=\operatorname{sigmoid}\left[\sum_{j=1}^{m} x_{j k}(t) \times w_{j k}(t)-w_{o k}\right]
$$

where $m$ is the number of inputs of neuron $k$ in the output layer.

Step 3: Weight training: Update the weights in the backpropagation network propagating backward the errors associated with output neurons.

A. Calculate the error gradient for the neurons in the output layer $\delta_{k}(t)$ :

$$
\delta_{k}(t)=Y_{k}(t) \times\left[1-Y_{k}(t)\right] \times \varepsilon_{k}(t)
$$

where $\varepsilon_{k}(t)=T_{k}(t)-Y_{k}(t)$.

Calculate the weight corrections $\Delta w_{j k}(t)$ :

$$
\Delta w_{j k}(t)=\alpha \times Y_{j}(t) \times \delta_{k}(t)
$$

where $\alpha$ is the learning rate, a positive constant inside a range $0,05<\alpha<0,75$.

Update the weights at the output neurons:

$$
w_{j k}(t+1)=w_{j k}(t)+\Delta w_{j k}(t)
$$

B. Calculate the error gradient for the neurons in the hidden layer $\delta_{j}(t)$ :

$$
\delta_{j}(t)=Y_{j}(t) \times\left[1-Y_{j}(t)\right] \times \sum_{k=1}^{l} \delta_{k}(t) w_{j k}(t)
$$

Calculate the weight corrections $\Delta w_{i j}(t)$ :

$$
\Delta w_{i j}(t)=\alpha \times x_{i}(t) \times \delta_{j}(t)
$$

Update the weights at the hidden neurons:

$$
w_{i j}(t+1)=w_{i j}(t)+\Delta w_{i j}(t)
$$

Step 4: Iteration. Increase iteration $t$ by one $t=t+1$, go back to the step 2 and repeat the process until the selected error criterion is satisfied.

Among the numerous artificial neural networks that have been proposed, backpropagation networks have been extremely popular for their unique learning capability [21]. $80 \%$ of practical ANNs applications used the backpropagation neural networks. Construction projects management effectiveness modelling by applying multilayer feedforward neural networks is presented in this study. 


\section{Construction projects management effectiveness modelling by applying neural networks}

Construction projects management effectiveness modelling by applying neural networks consists of the following stages:

- selection of the variables of the construction projects management effectiveness neural network model;

- selection and preparation of training data of the construction projects management effectiveness neural network model;

- designing and training the construction projects management effectiveness neural network;

- evaluation of the importance of a particular input factor to the construction projects management effectiveness neural network model output by applying a sensitivity analysis technique;

- identification of the determining construction key projects management effectiveness factors and modification of the construction projects management effectiveness neural network model;

- determining the validation range of the construction projects management effectiveness neural network model practical applications.
The construction projects management effectiveness neural network model had been developed using the NEURAL NETWORKS TOOLBOX 4.0 by MATLAB 6.0. Preparation of the training data and statistical computations had been performed by applying Microsoft Excel 2000.

Construction projects management factors are the input variables of the the construction projects management effectiveness neural network model. The output variable of that model is the construction projects management effectiveness in terms of construction cost variation.

A list of 27 construction management factors covering areas related to project manager, project team, project planning, organisation and control was collected according to the results of past research and opinion of experienced construction management practitioners (Table 2).

The construction project cost variation was calculated by equation:

$$
Q=\frac{P I-F I}{P I} \cdot 100 \%
$$

where $P I$ is estimated construction project cost; $F I$ is actual construction project cost.

Table 2. The importance of construction management effectiveness factors

\begin{tabular}{|c|c|c|}
\hline Category & Project management factor & Order of importance priority \\
\hline $\begin{array}{l}\text { Project manager } \\
(\mathrm{PM})\end{array}$ & $\begin{array}{l}\text { PM meetings } \\
\text { PM time devoted } \\
\text { PM site visits } \\
\text { PM subordinates } \\
\text { PM levels to craftsmen } \\
\text { PM education level } \\
\text { PM construction experience } \\
\text { PM project management experience } \\
\text { PM scope experience } \\
\text { PM technical experience } \\
\text { PM scope experience other than as PM } \\
\text { PM technical experience other than as PM }\end{array}$ & $\begin{array}{c}7 \\
16 \\
2 \\
10 \\
8 \\
11 \\
27 \\
15 \\
12 \\
13 \\
9 \\
14\end{array}$ \\
\hline Project team & $\begin{array}{l}\text { Team turnover } \\
\text { Design incentives }\end{array}$ & $\begin{array}{c}26 \\
1\end{array}$ \\
\hline Planning & $\begin{array}{l}\text { Design complete at construction start } \\
\text { Activities in execution plan } \\
\text { Budget contingency } \\
\text { Constructability program } \\
\text { Modularization }\end{array}$ & $\begin{array}{c}21 \\
19 \\
18 \\
5 \\
4\end{array}$ \\
\hline $\begin{array}{l}\text { Organization and } \\
\text { Control }\end{array}$ & $\begin{array}{l}\text { Progress inspection } \\
\text { Quality inspection } \\
\text { Safety inspection } \\
\text { Control system budget } \\
\text { Design control meetings } \\
\text { Construction control meetings } \\
\text { Schedule updates }\end{array}$ & $\begin{array}{c}23 \\
22 \\
17 \\
3 \\
20 \\
24 \\
6\end{array}$ \\
\hline & Budget updates & 25 \\
\hline
\end{tabular}


The present study is based on a set of data obtained in a questionaire survey on construction projects management effectiveness factors from contractor organisations in Lithuania and the United States of America in 2001. Twelve Lithuanian companies presented information on 32 completed construction projects. The average size for the projects is 4.3 million Litas and the mean duration is 7 months. 27 USA construction companies presented information on 54 completed construction projects with the average size of 30.1 million USD and the mean duration of 14 months. The training examples are subset of 76 projects data and the test examples are the rest 10 projects data.

A neural network works best when all its inputs and outputs vary within the range 0 and 1 . Thus all the data was classified and massaged before using them in a neural network. The input data - project management factors - was classified into six groups and the output data the percentage of the construction cost variation in loss or profit - was classified into five groups (Table 3).

Table 3. Classification of the project cost variation

\begin{tabular}{|c|c|c|}
\hline $\begin{array}{c}\text { Range of construction } \\
\text { project cost variation } \mathrm{Q}\end{array}$ & $\begin{array}{c}\text { Class } \\
\text { description }\end{array}$ & $\begin{array}{c}\text { Predicted neural } \\
\text { network output }\end{array}$ \\
\hline $\mathrm{Q}>+10 \%$ & Very good & 00001 \\
\hline$+3 \%<\mathrm{Q} \leq+10 \%$ & Good & 00010 \\
\hline$-3 \% \leq \mathrm{Q} \leq+3 \%$ & Average & 00100 \\
\hline$-10 \% \leq \mathrm{Q}<-3 \%$ & Bad & 01000 \\
\hline $\mathrm{Q}<-10 \%$ & Very bad & 10000 \\
\hline
\end{tabular}

The number of neurons in the input and output layer was decided by the number of input and output variables of the construction projects management effectiveness neural network. Thus, the input layer had 27 neurons and the output layer had 5 neurons, representing five classes of the construction cost variation. The number of hidden layers was determined during the neural network training.

The neural network was trained to solve the classification task by applying resilient backpropagation learning algorithm. The network performance in this study was measured by the modified reguliarisation error function:

$$
\text { msereg }=\gamma m s e+(1-\gamma) m s w,
$$

where $\gamma$ is the performance ratio; mse - the mean sum of squares of the network errors; $m s w=1 \sum_{n=1}^{n} w_{j}^{2}-$ the mean of the sum of squares of the network weights and thresholds.

The interpretation of the network output is based on the Bayesian posterior probability: the construction project cost variation belongs to the class represented by the output layer neuron of the highest output value.

The classification error was calculated by equation:

$$
C E_{R M S}=\sqrt{{ }_{n}^{l} \sum_{i}\left(T_{i}-P_{i}\right)^{2}},
$$

where $T_{i}$ - actual class of project cost variation; $P_{i}-$ class of project cost variation predicted by neural network; $i$ - construction project index; $n$ - number of examples for testing.

All construction management effectiveness factors were incorporated into the model at the first stage of model development. The initial network model comprised 27 neurons in the input layer with 9 neurons in the hidden layer and five neurons in the output layer.

A neural network is opaque. We can not see how the network derives its results. But we still need to grasp relationships between the network inputs and the results it produces. To understand the importance of a particular input to the network output we can use a sensitivity analysis technique

Sensitivity analysis was performed by measuring the network output, when each output-input was set (one at a time) to its minimum and then its maximum values. The amount of change in the network output represents the network's sensitivity to a respective input. Thus the importance of the construction management factors to the construction projects management effectiveness was evaluated (Table 2). The insignificant factors were trimmed from the network at the stage of model development. This was done gradually by eliminating the least important factors respectively to the results of sensitivity analysis. During this process 12 determining construction management effectiveness key factors were identified (Table 4). The final neural network model was built with 12 neurons in the input layer, 4 neurons in hidden layer and five neurons in the output layer (Fig 5).

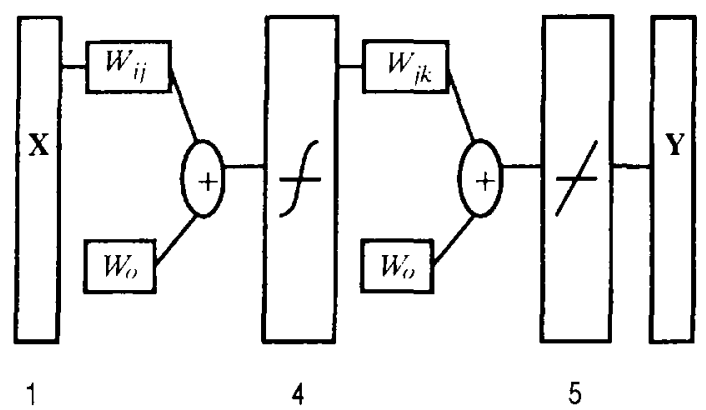

Fig 5. Scheme of the established ANN mo

The established construction projects management effectiveness neural network model represents the inputoutput functional relationships reflected by the specific characteristics of the training data set. Thus, the results are valid only within the range of the particular data set. Though, the analogic model can be developed by applying training data of any group of construction management institutions. 


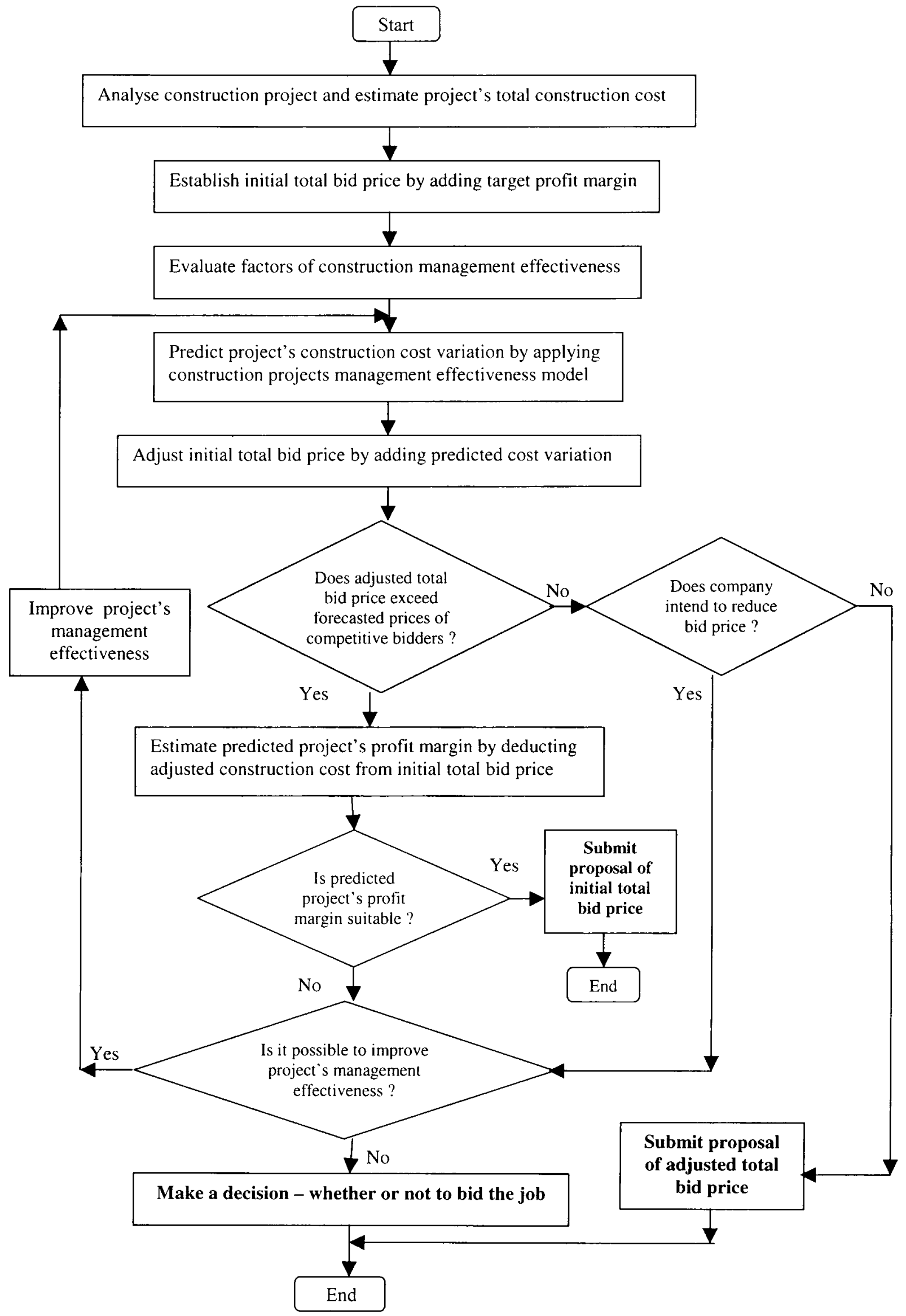

Fig 6. Construction projects management effectiveness evaluation algorithm 
Table 4. Key factors of construction management efectiveness

\begin{tabular}{|l|l|}
\hline \multicolumn{1}{|c|}{ Category } & \multicolumn{1}{|c|}{ Factors } \\
\hline $\begin{array}{l}\text { Project manager } \\
\text { (PM) }\end{array}$ & PM meetings \\
& PM site visits \\
& PM subordinates \\
& PM education level \\
& PM scope experience \\
& PM scope experience other than PM \\
\hline Project team & Design incentives \\
\hline \multirow{2}{*}{$\begin{array}{l}\text { Planning } \\
\text { Organisation } \\
\text { and control }\end{array}$} & $\begin{array}{l}\text { Constructability program } \\
\text { Modularisation }\end{array}$ \\
\hline
\end{tabular}

\section{Practical application of the construction projects management effectiveness neural network model}

Authors of the paper established the construction projects management effectiveness model and developed the application algorithm of that model for competitive bidding process (Fig 6). Civil engineers and managers are uniquely positioned to take use of the opportunities offered by the new paradigm.

The range of potential construction project cost variation can be evaluated by applying construction projects management effectiveness neural network model on the specific project, project team and construction company.

Case study: The request for bidding proposal to manage the construction project of 20 million Litas was issued by the Department of Transport. The type of the contract is a fixed price. Construction company $\mathrm{X}$ prepared bidding material for that project. Company's $\mathrm{X}$ estimated total bid price is 20,7 million Litas, $10 \%$ profit margin is included. According to the market analysis the competitive bids may fall into the range of 19-21 million Litas. What would be the company's $\mathrm{X}$ bidding decision?

Solution: The estimated construction cost was 18,82 million Litas. The predicted cost variation was calculated in the range from $-3 \%$ to $+3 \%$ by applying construction projects management effectiveness neural network model. If the worst happened, the construction cost increases by $3 \%$ up to 19,38 million Litas and the markup reduces to $6,8 \%$.

If the target markup for that project procurement was $10 \%$, the company should re-estimate the bid price up to 21,32 million Litas. Though, that price is not competitive. The company managers must make a major decision - whether to bid this project with the lower markup or strengthen the aspects of project management, thus resources can be deployed more effectively. By applying construction projects management effectiveness neural network model they can find the best possible arrangement of construction management effectiveness factors and examine the construction cost variation tendencies.

\section{Conclusions}

The paper presents a new methodology for construction projects management effectiveness modelling by applying artificial neural networks. The approach of artificial neural networks allows the construction projects management effectiveness model to be built and to determine the key determinants from a host of possible management factors that influence the project effectiveness in terms of budget performance.

A list of 27 construction management factors was collected according to the results of past research and opinion of experienced construction management practitioners. A survey questionnaire was developed and distributed to construction management companies in Lithuania and the USA. The historical data of project performance has been used to build the neural network model.

Altogether twelve construction management key factors were identified covering areas related to the project manager, project team, project planning, management and control.

The established neural network model can be used during competitive bidding process to evaluate management risk of construction project and predict construction budget performance. The model allows the construction project managers to focus on the key success factors and reduce the level of construction risk. The model can serve as the framework for further development of the construction management decision support system.

\section{References}

1. Ashley D. B., Lurie C. S., Jaselskis E. J. Determinants of construction project success. Project Management Journal, 1987, Vol 18, No 2, p. 69-79.

2. Jaselskis E. J., Ashley D. B. Optimal allocation of project management resources for achieving success. Journal of Construction Engineering and Management, 1991, Vol 117, No 2, p. 321-340.

3. Chua D. K. H., Kog Y. C., Loh P. K., Jaselskis E. J. Model for construction budget performance - neural network approach. Journal of Construction Engineering and Management, 1997, Vol 123, No 3, p. 214-222.

4. Chua D. K. H., Kog Y. C., Loh P. K. Critical success factors for different project objectives. Journal of Construction Engineering and Management, 1999, Vol 125, No 3, p. 142-150.

5. Millet R. A. Failures: how to avoid them. Journal of Management in Engineering, 1999, Vol 15, No 2, p. 32 36.

6. Mohsini R. A., Davidson C. H. Determinants or performance in the traditional building process. Construction Management and Economics, 1992, No 10, p. 343-359.

7. Tiong R. L. K. CSFs in competitive tendering and negotiation model for BOT projects. Journal of Construction Engineering and Management, 1996, Vol 122, No 3, p. 205-211. 
8. Molenaar K. R., Songer A. D. Web-based decision support systems: case study in project delivery. Journal of Computing in Civil Engineering, 2001, Vol 15, No 4, p. 259-267.

9. Chan A. P. C., Ho D. C. K., Tam C. M. Design and build project success factors: multivariate analysis. Journal of Construction Engineering and Management, 2001, Vol 127, No $2, p, 93-100$

10. Cheng E. W. L., Li H., Love P. E. D. Establishment of critical success factors for construction partnering. Journal of Management in Engineering, 2000, Vol 16, No 2, p. 84-92.

11. Back W. E., Moreau K. A. Cost and schedule impacts of information management on EPC process. Journal of Management in Engineering, 2000, Vol 16, No 2, p. 59--70.

12. Mitropoulos P., Tatum C. B. Management-driven information. Joumal of Management in Engineering, 2000, Vol 16, No 1, p. $48-58$.

13. Faniran O. O., Oluwoye J. O., Lenard D. J. Interactions between construction planning and influence factors. Journal of Construction Engineering and Management, 1998, Vol 124, No 4, p. 245-256.

14. Angelides D. C. Project management and good technical and business practices. Journal of Management in Engineering, 1999, Vol 15, No 3, p. 78-87.

15. Bower D., Ashby G., Gerald K., Smyk W. Incentive mechanisms for project success. Journal of Management in Engineering, 2002, Vol 18, No 1, p. 37-43.
16. Ford D. N. Achieving multiple project objectives through contingency management. Journal of Construction Engineering and Management, 2002, Vol 128, No 1, p. 30-39.

17. Jan J. C., Hung S. L., Chi S. Y., Chern J. C. Neural network forecast model in deep excavation. Journal of Computing in Civil Engineering, 2002, Vol 16, No 1, p.5965.

18. Juodis A. Construction industry in Europe: the market, management and development (Statyba Europoje: rinka, valdymas, plettra). Kaunas: Technologija, 2001. 185 p. (in Lithuanian).

19. Zavadskas E. K., Simanauskas L., Kaklauskas A. Decision support systems in construction (Sprendimu paramos sistemos statyboje). Vilnius: Technika, 1999. 236 p. (in Lithuanian).

20. Lu M., AbouRizk S. M., Hermann U. H. Estimating labor productivity using probability inference neural network. Journal of Computing in Civil Engineering, 2000, Vol 14, No 4, p. 241-248.

21. Adeli H., Wu M. Regularization neural network for construction cost estimation. Journal of Construction Engineering and Management, 1998, Vol 124, No 1, p. 18-24.

22. Sinha S. K., McKim R. A. Artificial neural network for measuring organizational effectiveness. Journal of Computing in Civil Engineering. 2000, Vol 14, No 1, p. 9-14.

23. Wasserman P. D. Advanced methods in neural computing New York: Van Nostrand Reinhold, 1993. 356 p.

24. Haykin S. Neural networks: a comprehensive foundation. New Jersey: Prentice-Hall, 1999. 649 p. 